\title{
Coordination in the presence of asset markets
}

\author{
Kogan, Shimon ; Kwasnica, Anthony M ; Weber, Roberto A
}

\begin{abstract}
We explore the relationship between outcomes in a coordination game and a pre-play asset market where asset values are determined by outcomes in the subsequent coordination game. Across two experiments, we vary the payoffs from the market relative to the game, the degree of interdependence in the game, and whether traders' asset payoffs are dependent on outcomes in their own or another game. Markets lead to significantly lower efficiency across treatments, even when they produce no distortion of incentives in the game. Market prices forecast game outcomes. Our experiments shed light on how financial markets may influence affiliated economic outcomes.
\end{abstract}

DOI: https://doi.org/10.1257/aer.101.2.927

Posted at the Zurich Open Repository and Archive, University of Zurich ZORA URL: https://doi.org/10.5167/uzh-52474

Journal Article

Published Version

Originally published at:

Kogan, Shimon; Kwasnica, Anthony M; Weber, Roberto A (2011). Coordination in the presence of asset markets. American Economic Review, 101(2):927-947.

DOI: https://doi.org/10.1257/aer.101.2.927 


\title{
Coordination in the Presence of Asset Markets
}

\author{
By Shimon Kogan, Anthony M. Kwasnica, and Roberto A. Weber*
}

Markets aggregate widely dispersed information and direct resources to where they produce the greatest value (Friedrich A. Hayek 1945; Adam Smith 1776). These dual roles of informational and allocative efficiency help explain why asset markets are often used to guide economic activity such as production and investment.

Many economic contexts involving production and investment are characterized by multiple equilibria (John Bryant 1983; Jack Hirshleifer 1983; Russell W. Cooper 1999; Colin Camerer and Marc Knez 1997; Jordi Brandts and David J. Cooper 2006). When asset markets are linked to such contexts, it is important to understand what role they play in aiding coordination and selecting equilibria. If asset markets obtain both informational and allocative efficiency in a multiple-equilibrium context, then they should coordinate the beliefs of economic agents and guide behavior to an efficient equilibrium. Indeed, some evidence suggests that one-sided auction markets may facilitate efficient coordination in an environment with multiple equilibria (John B. Van Huyck, Raymond C. Battalio, and Richard O. Beil 1993; Vincent Crawford and Bruno Broseta 1998). However, the broader question of whether asset markets generally lead to efficient coordination in environments with multiple equilibria remains an open question.

In this paper, we explore experimentally the influence of two-sided futures asset markets on behavior and outcomes in an economic activity characterized by multiplicity of equilibria. We use laboratory experiments, where we can control important features of both the market and the underlying activity, and focus on situations where the outcome of the economic activity is sensitive to the behavior of small numbers of agents. The economic activity in our setting consists of a coordination game with Pareto-ranked equilibria, in which the payoff to each player is a function of her own choice, or input, and group output, which is some order statistic (such as the minimum) of all players' input choices (see Van Huyck, Battalio, and Beil 1990; Van Huyck, Battalio, and Beil 1991; Crawford 1995). Players all do better if they coordinate on the highest-output (efficient) equilibrium, which is Pareto-optimal, but they also prefer to select a lower input if they believe others will do so.

Coordination games of this kind have been applied widely to model economic activity, from the relationship between beliefs and output in macroeconomic models (Cooper 1999), to public good provision (Hirshleifer 1983), to firm production

\footnotetext{
* Kogan: Department of Finance, McCombs School of Business, 1 University Station, B6600, Austin, TX 78712 (e-mail: shimon.kogan@mccombs.utexas.edu); Kwasnica: Smeal College of Business, The Pennsylvania State University, 332 Business, University Park, PA 16802 (e-mail: kwasnica@psu.edu); Weber: Department of Social and Decision Sciences, Carnegie Mellon University, Pittsburgh, PA 15101 (e-mail: rweber@andrew.cmu.edu). Financial support provided by The Center for Analytical Research in Technology (CART) and the Smeal College of Business Summer Grant program. We thank seminar participants at Boston College, Caltech, Cornell, MIT, NYU, University of Hawaii, University of Iowa, University of Southern California, University of Texas at Austin, University of Texas at Dallas, University of Toronto, 2007 Informs Meetings, 2007 North American ESA Meetings, 2009 NBER Behavioral Finance Meetings, and 2009 Utah Winter Finance Conference.
} 
(Camerer and Knez 1997; Brandts and Cooper 2006). ${ }^{1}$ Financial markets are often linked to these kinds of economic activity. Therefore, we study the relationship between economic performance, measured by outcomes in the coordination game, and a corresponding asset market in which the traded assets' values are contingent on the game outcome. In each period participants play the coordination game and receive payoffs from the outcome in the game. Prior to playing the game, participants trade in a market with Arrow-Debreu securities, each corresponding to one of the possible outcomes (output levels) in the game. ${ }^{2}$ Our primary purpose is to explore the extent to which markets influence outcomes in the underlying economic activity - that is, do markets guide behavior towards more or less efficient equilibria?

Previous experiments using similar games demonstrate that preplay communication can help reassure players of their mutual intent to pursue the efficient equilibrium and is thus effective for obtaining coordination on higher (more efficient) output (Andreas Blume and Andreas Ortmann 2007; Cooper, et al. 1992; Giovanna Devetag and Ortmann 2007). This includes communication that takes place through preplay market institutions; Van Huyck, Battalio, and Beil (1993) show how auctioning off the right to play a subsequent coordination game serves as a way for players to communicate their beliefs about what will happen in the game and, implicitly, their intended strategies (see Crawford and Broseta 1998). The result is that the one-sided auction markets used by Van Huyck, Battalio, and Beil (1993) lead to coordination on the efficient high-output equilibrium of the game.

However, the kind of implicit communication allowed by two-sided asset markets and the incentives created by such markets makes efficient coordination in their presence questionable. For starters, two-sided asset markets are much more complex and potentially noisy than the more simple kinds of explicit and implicit communication used in previous experiments. There exist separate markets for each equilibrium output level, and players' communication through the asset market may be difficult to interpret. For example, a player indicating a desire to buy assets corresponding to an inefficient equilibrium, even at a very low price, may create some doubt that the efficient equilibrium will result. Therefore, in contrast with previous results in which communication facilitates efficient coordination, preplay asset markets may also result in an opposite kind of market communication effect, one that leads players' beliefs to converge on the inefficient equilibrium, even if the underlying payoffs from the coordination game have not changed.

But the market may also exert an influence on outcomes in the game by affecting payoffs and incentives. In coordination games with high degrees of interdependence, as when output is determined by the lowest input choice by any single player, the incentives produced by preplay asset markets may result in coordination on lower-output (less efficient) equilibria. Through what we term portfolio incentive

\footnotetext{
${ }^{1}$ For example, Hirshleifer (1983) and Glenn W. Harrison and Hirshleifer (1989) discuss how production with high input-complementarity is present in collective responses to crises, where any input's failure can be disastrous. Brandts and Cooper (2006) note that this kind of game can exist on an assembly line, where the slowest worker determines the overall speed of production.

${ }^{2}$ Some markets trade explicit Arrow-Debreu securities, such as prediction markets designed to forecast future outcomes (Robert Forsythe et al. 1992) and Chicago Board of Trade binary options for macroeconomic variables (see http://www.clevelandfed.org/Research/data/Fedfunds/index.cfm). Even more markets provide implicit ArrowDebreu structured securities through the use of derivatives such as S\&P 500 index options (Yacine Ait-Sahalia and Andrew W. Lo 1998).
} 
effects, the asset market can create payoff-based incentives for players to invest in low output assets and then unilaterally decrease the group's output in the coordination game. A market may thus create an incentive to engage in opportunism, thereby harming output in the underlying economic activity.

Our first experiment explores these portfolio incentive effects by using a "weaklink" coordination game in which group output is determined by the lowest input by any player. In such a game, markets may lead to lower input choices, and the resulting inefficient equilibrium. Indeed, we find that the presence of a preplay asset market significantly reduces output. However, we also find that the distorted incentives produced by the market's presence cannot entirely explain the negative effect of the market on the game; the market lowers players' input choices even when there is no distortion of incentives. This suggests that, aside from any effect the market may have on payoffs, it may also negatively affect output by communicating negative beliefs.

In a second experiment we explore the extent to which asset markets influence outcomes in a coordination game with weaker interdependence among players. We use the case where output is determined by the second-lowest input choice in a group, so that the market creates no incentive for any player to unilaterally lower her input choice. In this game, all of the pure-strategy Nash equilibria to the coordination game are preserved in the presence of a preplay asset market, regardless of what happens during market trading, so portfolio incentive effects are minimized. But the market may nevertheless yield lower input choices if it amplifies pessimistic beliefs. Our second experiment confirms this market communication effect; we again find that the presence of an asset market universally lowers input choices and the resulting output levels.

Thus, across both our experiments we find a negative effect of asset markets on output (efficiency) that cannot be explained entirely by the distorted payoffs of a portfolio incentive effect. Indeed, we even find that asset markets decrease output for groups whose game payoffs are completely independent of the market (Outsiders, who trade in an asset market linked to another group's output). The overall pattern of effects we find is also consistent with a market communication effect, whereby prices and trading behavior appear to influence beliefs in a way that makes lowoutput equilibria more frequent. Therefore, in spite of the prior evidence suggesting that preplay communication mechanisms, including markets, facilitate efficient coordination, we find that such preplay institutions may also have detrimental effects and that such effects are not driven exclusively by distorted incentives.

In the next section, we present a model of a two-stage game involving a preplay asset market and a linked coordination game, which also serves as the basic framework for our experiments. We leave the formal analysis of the game for the online Appendix but refer to the main results in the text. Sections II and III present our two experiments.

\section{Model}

Players participate in a two-stage game consisting of an asset market followed by an order-statistic coordination game. The values of the securities traded in the asset market depend upon the realization of the output in the coordination game. 
In the second stage coordination game, each player simultaneously selects an input level $e_{i} \in\{1, \ldots, M\}$. Each player's payoff depends upon her own input level and the group's output, $m_{j}(e)$, which is determined by the input choices of all players:

$$
\pi_{i}(e)=a+b m_{j}(e)-c\left|m_{j}(e)-e_{i}\right|
$$

where $m_{j}(e)$ is the $j$ th order statistic of the $n$ chosen input levels, meaning that if input levels are ordered from low to high, or $e_{(1)} \leq e_{(2)} \leq \ldots e_{(n)}$, then $m_{j}(e)=e_{(j)}$. Assuming $b, c>0$, the pure-strategy Nash equilibria are completely characterized by any selection of identical inputs for all players. The Nash equilibrium with $e_{i}=M$ for all $i$ is the high output or efficient equilibrium and Pareto dominates any lower output equilibrium where $e_{i}=m$ with $m<M$ for all $i$.

When $j=1$ the coordination game is a version of the well-known "weak-link" or "minimum effort" coordination game first analyzed theoretically by Bryant (1983) and Hirshleifer (1983). Van Huyck, Battalio, and Beil (1990) conducted an early experimental study of the game and found two regularities replicated by subsequent studies (Knez and Camerer 1994; Weber et al. 2001; Weber 2006). First, groups often fail to coordinate on the Pareto-dominant equilibrium. Second, group size exerts a strong influence on equilibrium selection. Small groups of two to three players converge to much higher output levels than larger groups of six or more.

Other order statistic games where $j>1$ have also been studied (Van Huyck, Battalio, and Beil 1991; Van Huyck, Battalio, and Frederick W. Rankin 2007). Generally, higher order statistics facilitate coordination on equilibria corresponding to higher input choices. However, even when $j>1$ efficient coordination is not trivial. Groups often end up at equilibrium output levels well below $M$, the result of a strong path dependence whereby initial output outcomes determine subsequent input choices. See Colin F. Camerer (2003), Chapter 7, for a review of experiments on order-statistic coordination games.

Prior to the coordination game all players participate in an asset market. In the market, the value of a traded security is based upon the output, $m_{j}(e)$, in the subsequent coordination game. More precisely, there are $M$ state-contingent securities traded with the following payoffs:

$$
X_{m}=\left\{\begin{array}{ll}
\beta & \text { if } m_{j}(e)=m \\
0 & \text { otherwise }
\end{array},\right.
$$

where $\beta>0$.

At the conclusion of trading in the asset market, all players possess a particular portfolio $x_{i}=\left(x_{1 i}, x_{2 i}, \ldots, x_{M i}\right)$ of securities where $x_{m i}$ is player $i$ 's units of asset $X_{m}$. Since these assets pay off based upon the outcome of the game, the original game payoffs from (1) are modified to be:

$$
\bar{\pi}_{i}\left(e ; x_{i}\right)=a+b m_{j}(e)-c\left|m_{j}(e)-e_{i}\right|+\beta \sum_{m=1}^{M} \delta_{m}(e) x_{m i},
$$

where $\delta_{m}=1$ if $m_{j}(e)=m$ and 0 otherwise. We call this game the market-modified coordination game. 
We assume that the aggregate endowment for each asset is the same, or $\sum_{i=1}^{n} x_{m i}=k$ for all $m$. Under this assumption, the market is a constant-sum game, and therefore the efficiency properties of higher matched inputs in the market-modified coordination game are the same as in the original coordination game. However, different ex post portfolios can affect individual players' incentives to select particular input levels.

In the online Appendix, we present a theoretical analysis of how the incentives produced by the market may affect behavior in the modified coordination game. Our two main results (propositions 1 and 2) show that when output in the coordination game is determined by the lowest input choice $(j=1)$ the asset market distorts players' incentives to the point where equilibria involving input choices greater than 1 can be ruled out, but that for higher order statistics $(1<j<n)$ the set of equilibria are unchanged. We discuss these predictions and the intuition behind them in more detail when discussing our experiments in the next two sections.

\section{Experiment 1-Minimum-Input Coordination $(j=1)$}

Our first experiment explores the special case where $j=1$ and the output of the coordination game is determined by the lowest input. Such a high degree of interdependence means that players may have an incentive to unilaterally decrease output.

One reason this can occur is that a player's portfolio holdings, $x_{i}$, at the end of the trading period may modify her incentives in the game. An input level $m$ for all players will remain a pure strategy equilibrium of the game only if for all players $i$ and for all lower output levels $\ell<m,{ }^{3}$

$$
x_{\ell i}-x_{m i} \leq\left[\frac{b}{\beta}\right](m-\ell) .
$$

When a player has enough of an asset that pays off under lower output (relative to higher output assets), she has a weakly dominant strategy to play the corresponding lower input. Thus, the lowest input choice, $e_{i}=1$, by all players is the only Nash equilibrium that exists for every possible asset portfolio. For higher output outcomes, the relative payoff of the asset market $(\beta)$ to the coordination game $(b)$ determines the asset portfolios that support equilibria of the market-modified game. This result suggests that the market may lead to lower output in the game, and that the extent to which it does so will be greater when the payoff from the market assets $(\beta)$ is large relative to the payoffs from the game $(b)$.

In order to examine this potential direct portfolio incentive effect in our experiment, we systematically varied the payoffs from the market relative to those from the game. In the Market $H$ variant we set $b / \beta=2$ and in the Market $L$ variant, we set $b / \beta=40$. Thus, the Market $L$ treatment significantly lowered the relative payoff of the market. In order to see the potential strength of this treatment, consider the differences in asset holdings that would be necessary to induce an individual to be unwilling to play the input level $e_{i}=4$. In the Market $H$ treatment, the individual would have to hold greater than 2,4 , or 6 , more units of the $X_{3}, X_{2}$, or $X_{1}$ assets

\footnotetext{
${ }^{3}$ See Proposition 1 in the online Appendix for a proof.
} 
respectively (than units of the $X_{4}$ asset). Whereas, in the Market $L$ treatment, the required minimum differences are 40,80, and 120 . Therefore, the condition in (4) predicts a likely much stronger negative effect of the market in the Market $H$ treatment than in Market L.

The above prediction relies on ex post asset allocations and therefore ignores the strategic nature of trading behavior, whereby participants in the market know what strategy they are likely to play in the game, and the market serves to aggregate this information. Moreover, players most likely jointly determine their trading strategies and game actions in the two stages of the market and game. To analyze this aspect of behavior in the two-stage game, we adopt a rational expectations framework in which the market fully aggregates players' beliefs and behavior in the game is consistent with such beliefs. The only rational expectations equilibrium when $j=1$ is the inefficient one in which all players select the lowest input choice $\left(e_{i}=1\right) .{ }^{4}$ Any player can unilaterally assure that the final output is 1 by selecting $e_{i}=1$. This means that the only prices that are consistent with an equilibrium in both stages of the game must price the low output asset $X_{1}$ at $\beta$, meaning that low output will occur with probability 1 . If the price of the low output asset is lower than $\beta$ then any player can profit by buying units of the low output asset, and once that player has a sufficient number of these low output assets the player has a weakly dominant strategy to select the low input level $e_{i}=1$.

Our experiment tests the above predictions about the effects of an asset market, relative to a Control treatment in which there is no market. In contrast with prior evidence of the beneficial effects of institutions that allow preplay communication, including markets, our theoretical analysis predicts that preplay asset markets will have a negative effect on output levels in the game. We vary several features of the game and the market to better understand the precise relationship between the two. As we mention above, we vary the incentives of the market relative to the game (Market $L$ versus Market $H$ ). We also vary the group size in which the game is played. Finally, to explore whether the market affects behavior and outcomes in the game even when the two are strategically independent, we include an Outsiders treatment in which players trade in a market that is unrelated to their coordination game. This final treatment allows us to determine the extent to which the market can influence behavior and outcomes in the coordination game, absent any portfolio incentive effects.

\section{A. Experimental Design}

Each experimental session consisted of eight periods, all identical in structure. In each period, every subject submitted a number, corresponding to her input choice in the coordination game. The input choice took one of four values: $e_{i}=\{1,2,3,4\}$. The payoff function was the same as in (1) with output determined by the minimum input choice $(j=1)$. The parameters used were $a=\$ 1.20, b=\$ 0.20$, and $c=\$ 0.20$. Thus, the payoff for the efficient equilibrium in the coordination game

${ }^{4}$ See Proposition 2 in the Online Appendix for a formal statement and proof. 
Table 1-Minimum-Input Game Payoff Table (Exp 1)

\begin{tabular}{cc|cccc}
\hline \hline \multicolumn{5}{c}{} & \multicolumn{5}{c}{$\begin{array}{c}\text { Minimum input } \\
\text { (output) }\end{array}$} \\
& & 4 & 3 & 2 & 1 \\
\hline & 4 & 2.00 & 1.60 & 1.20 & 0.80 \\
Player's & 3 & & 1.80 & 1.40 & 1.00 \\
input & 2 & & & 1.60 & 1.20 \\
& 1 & & & & 1.40 \\
\hline
\end{tabular}

was $\$ 2.00$. These parameters give rise to the payoff table displayed in Table 1, which is identical to the one presented to all subjects. ${ }^{5}$

Each subject was assigned to a group, which did not change throughout the experiment. Each session consisted of both Small three-person groups and Large sixperson groups. All subjects knew their group assignment and the size of their group and the other groups. Throughout the session, no communication between subjects was permitted and all instructions, choices, and information were transmitted via the computer terminal, utilizing the z-tree program (Urs Fischbacher 2007). ${ }^{6}$

In the Control treatment subjects simply played the coordination game for eight periods. In the Market conditions, prior to playing the game in a period, subjects first traded in an asset market in which securities' liquidating values depended upon the output in the coordination game. ${ }^{7}$ Trading took place anonymously over an electronic double-auction market lasting approximately six minutes. During that time subjects were free to submit limit orders, which were posted to the limit-order book, or to accept limit orders submitted by others. In addition to being able to see the five highest (lowest) current limit orders to sell (buy) for any security, subjects could view the entire trading price history for every security. ${ }^{8}$

Prior to trading, groups were assigned to markets such that the number of traders per market was fixed at nine. We kept the number of market traders constant across the Small and Large group treatments in order to control for the possibility that market size might affect the performance of the market, and to allow a comparison between Insider and Outsider traders. This was achieved by conducting two parallel sets of markets, each populated by one Small group and one Large group. In one set of markets the value of the securities was determined by the output of a Small group, and in the second the value of the securities was determined by the output of a Large group. ${ }^{9}$

\footnotetext{
${ }^{5}$ The parameterization of the minimum-input game differs from that in Van Huyck, Battalio, and Beil (1990) and most other coordination game experiments in that there are fewer input level choices available. This was necessary in order to keep the number of traded securities reasonable.

${ }^{6}$ Screen shots of the instructions and market trading platform are provided in the online Appendix.

${ }^{7}$ In two of the market treatment sessions, only six market periods were conducted due to time considerations. In both cases, subjects still participated in eight game periods with their initial endowment taken as their payoff from the market for the final two periods.

${ }^{8}$ In order to ensure that subjects understood the market operation, they completed a short quiz and were given the opportunity to ask questions in a practice trading round that was not linked to any game outcome.

${ }^{9}$ A typical session divided 18 subjects into four groups as follows: groups $A$ and $C$ were Small groups, and groups $B$ and $D$ were Large groups. Market 1 included members from groups $A$ and $B$ trading securities linked to the output of group $A$, and Market 2 included members from groups $C$ and $D$ trading securities linked to the output of group $D$.
} 
At the beginning of each trading stage, subjects were endowed with units of the different assets and with an interest-free loan of cash. The endowments varied across subjects and across periods, but the aggregate endowment at the beginning of each trading period was equal across securities at 54 units. ${ }^{10}$ The aggregate endowment did not constrain further trading; subjects could sell each asset short. ${ }^{11}$

The Market $H$ and Market $L$ treatments varied the value of the asset market relative to the game in order to examine the influence of the portfolio incentive effect we describe above. In the Market $H$ treatment, we set $b / \beta=2$ by setting the binary payoff of each asset at $\beta=\$ 0.10$ whereas in the Market $L$ treatment we set $b / \beta=40$ by setting $\beta=\$ 0.005 .{ }^{12}$

Each market contained two types of traders. Insiders were subjects who traded on outcomes that they could directly influence, meaning that their own game determined asset values. Outsiders traded on an exogenous outcome, meaning that asset values were determined by the outcome of the other group's game. Our theoretical analysis of portfolio incentive effects (see the Online Appendix) only applies to Insiders, whose input choices affect the liquidation value of their asset holdings. For Outsiders, the value of their asset holdings is completely independent of output in their own coordination game. Thus, the set of Nash equilibria for the Outsiders' game is unaffected by the presence of an asset market and is the same as in the Control treatment. However, Outsiders might still be affected by potential market communication effects; they observe market prices and may believe that those prices also provide information about the intended play in their group.

At the end of the market trading stage, subjects participated in the coordination game. Then, subjects' positions in the securities were liquidated according to the appropriate group's output. Subjects observed the anonymous distribution of input choices in their own group as well as the input choices made by subjects in the other group (of the other size) participating in their market. The feedback from the game provided to subjects in all variants of the experiment was the same; in the Control treatment, subjects were also informed of the choices in their group as well as those in a group of the other size.

The experiment was conducted at the Laboratory for Economic Management and Auctions (LEMA) at The Pennsylvania State University, between October 2006 and October 2007. Panel A in Table 2 describes the data collected. In every condition, half $(8,12$, and 8 respectively) of the groups were Large and the other half were Small. In the two Market conditions, half of the groups were Insiders and the other half were Outsiders. No subject appeared in more than one session. Participants received a show-up fee of $\$ 6$ and an additional performance-based payment averaging \$13.18 (Control), \$15.17 (Market H), and \$11.40 (Market L). In the Market

\footnotetext{
${ }^{10}$ For every asset, two subjects in each period had an endowment of 24 units of that particular asset and none of the other three assets. One subject in each period had an endowment of six units of each of the four assets. The choice of asymmetric endowments (across subjects) is common in these types of asset markets and was designed to stimulate trading by providing participants with rebalancing motives.

${ }^{11} \mathrm{~A}$ margin requirement was used to ensure that no subject's short sales exceeded the amount of their cash loan, resulting in losses beyond that loan.

${ }^{12}$ The parameter amounts for the game and market were expressed to subjects in "experimental dollars," and the appropriate exchange rate was selected so that, in both treatments, the liquidation values of the assets were exactly 1 experimental dollar. This allowed prices to potentially directly reveal probabilistic information in both Market treatments. The values in the coordination game were also varied accordingly so as to keep the same dollar payoff from the coordination game for all treatments.
} 
Table 2-Summary of the Data Collected

\begin{tabular}{lccc}
\hline \hline & Control & Market H & Market L \\
\hline Panel A. Experiment 1 & & & 7 \\
Sessions & 4 & 6 & 16 \\
Groups & 16 & 24 & 72 \\
Individuals & 72 & 108 & \\
& & & 4 \\
Panel B. Experiment 2 & 3 & - & 16 \\
Sessions & 12 & - & 72 \\
Groups & 54 & - & \\
Individuals & & & \\
\hline
\end{tabular}

treatments, the payments from the markets contributed on average $\$ 4.85$ (Market $H$ ) and $\$ 0.25$ (Market $L)$ to this total. Market sessions lasted around two hours.

\section{B. Results}

Insider Group Output-We first explore the effects of our market treatments on output for Control versus Insider groups. As depicted in Figure 1, across all eight periods, mean output differed considerably by treatment. Small Control groups obtained coordination on mean output levels very close to the efficient level, while Large groups coordinated on output of around 2.4. ${ }^{13}$ As predicted, for Insider groups mean output was lower in both Market treatments, relative to the Control, and this effect was stronger when market incentives were high.

In Table 3, we examine the relationship between group output, Market treatments, and group size. We use ordered probit regressions, which take into account the ordinal nature of output, and estimate a model that includes group random effects. The Market treatments produce output that is substantially lower compared with the Control treatment (columns 1,2, and 3); this result also holds when controlling for group size. ${ }^{14}$ As expected, group output is lower for large groups. Finally, we observe that in the Market $H$ treatment output is reduced further than in the Market $L$ treatment, when controlling for group size (column 3 ). ${ }^{15}$

These findings suggest that, consistent with our predictions, the presence of an asset market in conjunction with a minimum-input coordination game significantly lowers output levels for all Insider group sizes and periods. These results stand in contrast to the findings of Blume and Ortmann (2007), Cooper et al. (1992), and Van Huyck, Battalio, and Beil (1993), which show that other forms of preplay

\footnotetext{
${ }^{13}$ This is higher than is typically the case for large groups, which usually converge to the least efficient equilibrium. However, our experiment differs from many previous experiments in important ways: it uses fewer input choices (e.g., 4 versus 7 in Van Huyck, Battalio, and Beil 1990), has smaller group sizes (e.g., 3 and 6 versus 14 and 16 in Van Huyck, Battalio, and Beil 1990), provides subjects with the full history of choices by other players, and also shows players in each Large group the performance of a Small group (Gary Bornstein, Uri Gneezy, and Rosmarie Nagel 2002). While these factors may influence behavior in our experiment, relative to other experiments using similar coordination games, they are constant across all our treatments. Also, consistent with previous research, output generally fell (though slightly) across periods in the Control-Large treatment-e.g., by period 8 mean output was 1.9.

${ }^{14}$ Throughout this section, unless noted otherwise, we analyze data obtained from Insider groups only.

${ }^{15}$ We find that markets have similar negative and significant effects when we look at Period 1 results only and when we treat each group as a single observation consisting of that group's median output level over the last five periods of the experiment.
} 


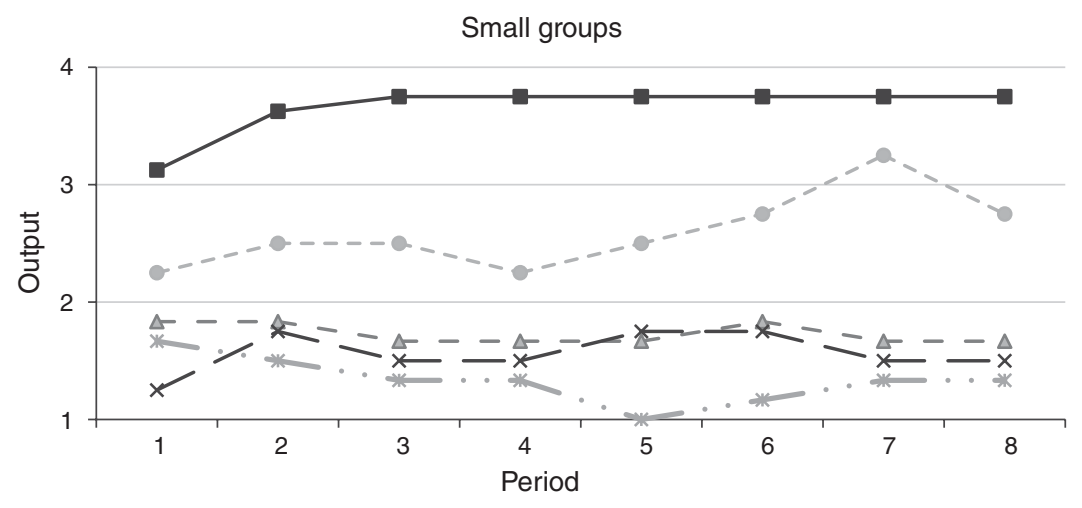

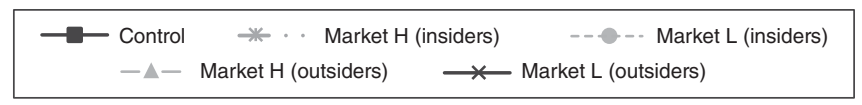

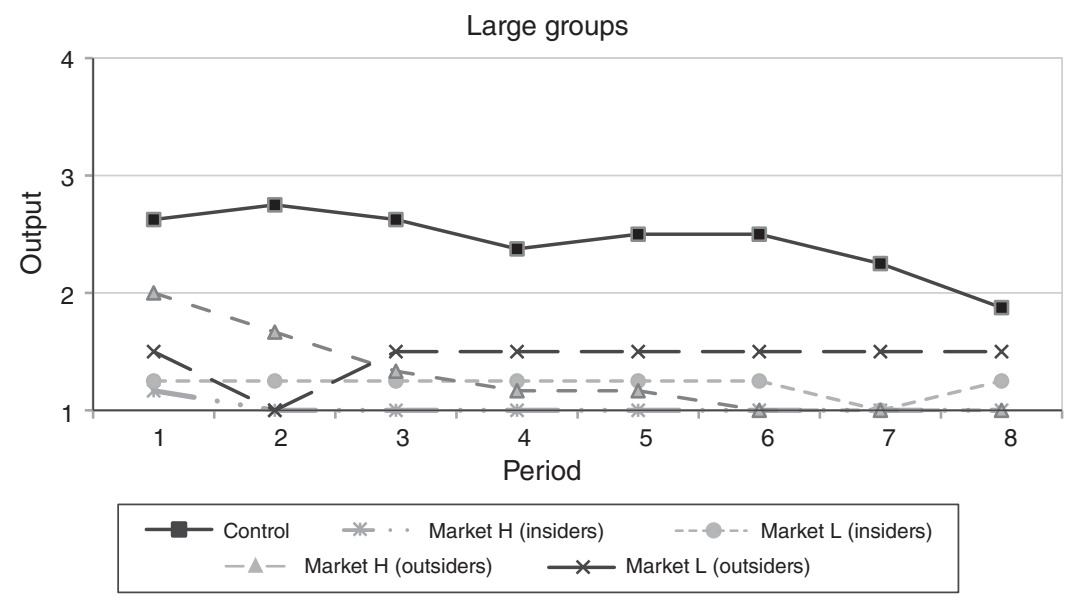

Figure 1. Average Group Output across Periods (Exp 1)

communication, including an auction market, produce coordination on higher output levels. To better understand what drives these results we turn to study two asset market dimensions that can influence behavior: portfolio incentives and security prices.

Portfolio Incentives-For Insiders, players' asset positions when $j=1$ may negatively influence output through a distortion of individual incentives. Players who hold enough low-output assets may prefer to make low-input choices, regardless of their beliefs about others' behavior. This suggests a positive relationship between the amount of an asset an individual Insider holds, and the likelihood that individual will select the corresponding input. Moreover, we expect these portfolio incentives to be stronger when market incentives are high than when they are low.

Table 4 shows the results obtained from probit regressions of individuals' input choices on their end-of-period portfolio holdings of securities 1, 2, 3, and 4, when taking into account market level random effects. We find that subjects who choose 
Table 3-Group Output by Condition Relative to Control (Exp 1)

\begin{tabular}{|c|c|c|c|c|c|c|}
\hline \multirow[b]{3}{*}{ Market } & \multirow{2}{*}{$\begin{array}{l}\text { (1) } \\
\text { Group output: }\end{array}$} & \multirow{2}{*}{$\begin{array}{c}(2) \\
\text { Insiders (ver }\end{array}$} & \multirow{2}{*}{$\begin{array}{c}(3) \\
\text { us Control) }\end{array}$} & \multirow{2}{*}{$\begin{array}{c}\text { (4) } \\
\text { Group output: }\end{array}$} & \multirow{2}{*}{\multicolumn{2}{|c|}{$\begin{array}{c}(5) \\
\text { Outsiders (versus Control) }\end{array}$}} \\
\hline & & & & & & \\
\hline & $\begin{array}{l}-3.936 * * * \\
{[0.485]}\end{array}$ & $\begin{array}{l}-3.809 * * * \\
{[0.655]}\end{array}$ & $\begin{array}{l}-3.877 * * * \\
{[0.431]}\end{array}$ & $\begin{array}{l}-4.269 * * * \\
{[0.661]}\end{array}$ & $\begin{array}{l}-4.168 * * * \\
{[0.623]}\end{array}$ & $\begin{array}{l}-4.587 * * * \\
{[0.681]}\end{array}$ \\
\hline Market $\mathrm{H}$ & & $\begin{array}{c}-1.636 \\
{[1.237]}\end{array}$ & $\begin{array}{c}-2.614 * * * \\
{[0.425]}\end{array}$ & & $\begin{array}{c}-0.36 \\
{[0.292]}\end{array}$ & $\begin{array}{c}0.213 \\
{[0.371]}\end{array}$ \\
\hline Large group & & & $\begin{array}{c}-1.241 \text { *** } \\
{[0.138]}\end{array}$ & & & $\begin{array}{c}-0.667 * * * \\
{[0.140]}\end{array}$ \\
\hline Period & $\begin{array}{l}-0.02 \\
{[0.059]}\end{array}$ & $\begin{array}{c}-0.019 \\
{[0.060]}\end{array}$ & $\begin{array}{c}-0.023 \\
{[0.063]}\end{array}$ & $\begin{array}{r}-0.079 \\
{[0.060]}\end{array}$ & $\begin{array}{c}-0.079 \\
{[0.059]}\end{array}$ & $\begin{array}{c}-0.079 \\
{[0.061]}\end{array}$ \\
\hline $\begin{array}{l}\text { Observations } \\
\text { Log likelihood }\end{array}$ & $\begin{array}{c}288 \\
-176.79\end{array}$ & $\begin{array}{c}288 \\
-173.41\end{array}$ & $\begin{array}{c}288 \\
-161.85\end{array}$ & $\begin{array}{c}288 \\
-194.82\end{array}$ & $\begin{array}{c}288 \\
-193.96\end{array}$ & $\begin{array}{c}288 \\
-194.46\end{array}$ \\
\hline
\end{tabular}

Notes: Ordered probit regression with group random effects; Huber-White standard errors.

*** Significant at the 1 percent level.

** Significant at the 5 percent level.

* Significant at the 10 percent level.

Table 4-Individual Portfolio Holdings and Input Choices (Exp 1, Insiders)

\begin{tabular}{lcccc}
\hline \hline Holdings & Input $=1$ & Input $=2$ & Input $=3$ & Input $=4$ \\
\hline Security 1 & $(1)$ & $(2)$ & $(3)$ & $(4)$ \\
& $0.043^{* * *}$ & $-0.015^{* * *}$ & $-0.031^{*}$ & $-0.014^{* *}$ \\
Security 2 & {$[0.009]$} & {$[0.005]$} & {$[0.017]$} & {$[0.006]$} \\
& -0.017 & $0.034 * * *$ & -0.007 & $-0.014 * * *$ \\
Security 3 & {$[0.012]$} & {$[0.009]$} & {$[0.007]$} & {$[0.004]$} \\
& -0.012 & $-0.024 * * *$ & $0.043 * * *$ & -0.004 \\
Security 4 & {$[0.010]$} & {$[0.007]$} & {$[0.015]$} & {$[0.005]$} \\
& -0.012 & -0.001 & -0.018 & $0.025^{* *}$ \\
Constant & {$[0.011]$} & {$[0.008]$} & {$[0.011]$} & {$[0.011]$} \\
& -0.282 & $-1.003 * * *$ & $-1.529 * * *$ & $-0.730^{* * *}$ \\
Observations & {$[0.194]$} & {$[0.177]$} & {$[0.358]$} & {$[0.115]$} \\
Fraction & 720 & 720 & 720 & 720 \\
Log likelihood & 0.453 & 0.186 & 0.142 & 0.219 \\
& -365.13 & -275.11 & -191.72 & -280.92 \\
\hline
\end{tabular}

Notes: Probit regression with market random effects; Huber-White standard errors.

*** Significant at the 1 percent level.

** Significant at the 5 percent level.

* Significant at the 10 percent level.

an input level $m$ hold more $m$ security units and fewer non- $m$ security units. For example, column 1 in the table indicates that subjects are more likely to choose an input level of 1 with every additional unit of asset $X_{1}$ held. In this case, increased holdings of assets $X_{2}, X_{3}$, and $X_{4}$ have a negative, although not statistically significant, effect. Similar patterns emerge if we look at the other input levels; all diagonal elements are positive and statistically significant, while all off-diagonal elements in these columns are negative. ${ }^{16}$ Further, these results hold with similar magnitude for both the Market $H$ and the Market $L$ treatments. ${ }^{17}$

\footnotetext{
${ }^{16}$ Subjects shorted assets in a substantial number of cases. Overall, 21 percent of the final portfolio holdings included a short sell of at least one of the four assets in the Market $H$ condition and 27 percent in the Market $L$ condition. However, we do not find that subjects' input choices are abnormally influenced by short sells.

${ }^{17}$ This relationship also generally rules out "hedging" by players who adopt different asset positions than their intended play in the coordination game in order to lower payoff variability.
} 
Table 5-Portfolio Holdings and Equilibrium Selection (EXP 1)

\begin{tabular}{|c|c|c|c|c|c|c|}
\hline & $\{1\}$ & $\{1,2\}$ & $\{1,2,3\}$ & $\{1,2,3,4\}$ & Overall & Control \\
\hline \multicolumn{7}{|c|}{ Panel A. Small groups } \\
\hline Output $=4$ & 0.03 & 0.00 & 0.00 & 0.29 & 0.13 & 0.72 \\
\hline Output $=3$ & 0.09 & 0.11 & 0.33 & 0.26 & 0.16 & 0.23 \\
\hline Output $=2$ & 0.06 & 0.11 & 0.00 & 0.26 & 0.14 & 0.03 \\
\hline Output $=1$ & 0.82 & 0.78 & 0.67 & 0.19 & 0.58 & 0.02 \\
\hline Observations & 34 & 9 & 3 & 31 & 80 & 64 \\
\hline \multicolumn{7}{|c|}{ Panel B. Large groups } \\
\hline Output $=4$ & 0.00 & 0.00 & 0.00 & 0.00 & 0.00 & 0.23 \\
\hline Output $=3$ & 0.00 & 0.00 & 0.00 & 0.00 & 0.00 & 0.30 \\
\hline Output $=2$ & 0.02 & 0.00 & 0.00 & 0.30 & 0.10 & 0.14 \\
\hline Output $=1$ & 0.98 & 1.00 & 0.00 & 0.70 & 0.90 & 0.33 \\
\hline Observations & 46 & 2 & 0 & 23 & 80 & 64 \\
\hline
\end{tabular}

Given that individuals' choices are related to their portfolio holdings, we test the implications of the portfolio incentive effect more directly by computing the set of Nash equilibria that persist in the coordination game after trading in the market. For each group and period we find the set of pure-strategy equilibria that are incentive compatible with subjects' ex post security holdings and the modified payoffs of the game. Table 5 presents the observed distributions of group output for different realized sets of equilibria remaining in the game modified by ex post asset holdings. For example, column 2, labeled " $\{1,2\}$," reports the frequency of different output levels observed when only matched input levels of 1 or 2 remain Nash equilibria of the market-modified coordination game following trading (i.e., satisfy the condition in (4)). Panel A reports the results for Small groups, while panel B reports the results for Large groups. For comparison, we include the corresponding distribution of output choices observed in the Control treatment in the last column, where game payoffs are not modified by the market so the set of equilibria is always $\{1,2,3,4\}$.

Final portfolio holdings' influence on the set of pure-strategy equilibria is also reflected in behavior; observed behavior rarely falls outside the set of equilibria that are consistent with subjects' holdings (see the first three columns). Thus, portfolio incentive effects can account for some of the decline in output in the presence of asset markets. But, even when holding the set of equilibria constant, we find that for both Small and Large groups, output levels are substantially lower in the Market treatments than in the Control treatment. This is apparent when contrasting the distribution of group output when portfolio incentives do not eliminate any of the equilibria (column labeled " $\{1,2,3,4\}$ ") with the distribution of group output in the Control treatment. For example, 70 percent of the Large groups in the Market treatments, for which portfolio holdings did not eliminate any of the equilibria, selected output of 1 compared with 33 percent in the Control treatment. If we use ordered probit random-effects regressions (such as the one used in Table 3), using only cases for the Market treatments in which all four pure-strategy equilibria remain as equilibria to the market-modified game (i.e., the observations in column " $\{1,2,3,4\}$ "), we again find a negative and statistically significant effect for the market treatments. Thus, while portfolio incentive effects appear to be at least partly responsible for the 
decrease in output in the presence of markets, they cannot alone account for the full set of findings. The presence of asset markets leads to significantly lower output, even when the set of equilibria in the market-modified coordination game are unaffected. ${ }^{18}$

Outsiders' Behavior-Recall that the Market treatments contained both Insiders and Outsiders. The two groups differ in that Outsiders' incentives in the coordination game are unaffected by the presence of markets. If portfolio incentive effects are the only channel through which markets affect behavior, Outsiders' output levels should resemble those in the Control treatment. However, Outsiders' beliefs may be affected by prices and trading in the market that is unrelated to their game, allowing a possible market communication effect to influence their game's output similarly to the effect the market has on Insider groups.

Returning to Figure 1, we see that Outsider groups' output is considerably lower than in the Control. In fact, they obtain output levels very close to those observed for Insider groups. Columns 4 through 6 in Table 3 compare output for Control and Outsider groups, using ordered probit regressions with random effects. The results confirm that Outsiders' output is significantly lower than that of Control groups. ${ }^{19}$

These results are anomalous if one holds the view that the presence of markets affects behavior entirely through portfolio incentive effects. Outsiders' incentives in the coordination game are unchanged by the presence of the asset market, so any explanation for lower output among Insiders that is based only on modified incentives cannot explain why Outsider groups' output changes in a very similar manner.

Price Informativeness-Since portfolio incentive effects alone do not fully account for the detrimental effect of markets on output, we turn to study the role of market prices. Market trading behavior, including prices, could serve as a form of communication, coordinating players' beliefs regarding expected output. Such a market communication effect, which could influence both Insider and Outsider groups, would rely on prices to provide information about the subsequent output level. Our theoretical analysis assumes that market prices fully reveal future output. We find that prices affect individual input choices. Indeed, the correlation between the fraction of subjects who choose a given input level $m$ and the average closing price of security $m$, for all securities, is 0.45 and is statistically different from zero at the 1 percent level.

We also examine the informativeness of market prices about the subsequent group output. We create a measure of price-based expected output by multiplying the standardized prices by the corresponding output associated with that asset. ${ }^{20}$ Table 6 shows, using ordered probit regressions of group output on price-based expected

\footnotetext{
${ }^{18}$ Recall that the only fully revealing rational expectations equilibrium when $j=1$ involves output equaling 1 and the market forecasting this outcome (see Proposition 2 in the online Appendix). If we take the market forecast as the output level with the highest market price in the trading period, we find support for this equilibrium prediction. In 58 percent of all periods for Insider groups, the highest price corresponds to an output of 1 , and the subsequent output equals 1 . This proportion is slightly higher for Market $H$ (66 percent) than for Market $L$ ( 47 percent). In the first period, 35 percent of groups conform to the prediction.

${ }^{19}$ The difference between Insider and Outsider output is not statistically significant. In testing whether Outsiders hold different end-of-period portfolios compared with Insiders, we find no statistical difference.

${ }^{20}$ For example, if the prices of assets 1 and 2 are 0.5 each, the price-based expected output would be equal to 1.5. We use the average price over the last five trades (in each period) as our measure of market price for that period. When less than five trades are completed, we average all the trades conducted in that market and period. As is
} 
Table 6-Security Prices ANd Group OutPut (EXP 1, Insiders)

\begin{tabular}{lcccc}
\hline \hline & \multicolumn{4}{c}{ Group output } \\
\cline { 2 - 5 } & $(1)$ & $(2)$ & $(3)$ & $(4)$ \\
\hline Expected output & $1.411^{* * *}$ & $1.418 * * *$ & $1.392^{* * *}$ & $1.311^{* * *}$ \\
& {$[0.299]$} & {$[0.232]$} & {$[0.264]$} & {$[0.318]$} \\
Market H & & $-1.068^{*}$ & & $-1.237 * *$ \\
Large group & & & & {$[0.596]$} \\
& & & $-0.454]$ & $-0.786^{* *}$ \\
Last period & $1.329 * * *$ & $1.254 * * *$ & $1.261 * * *$ & {$[0.382]$} \\
output & {$[0.286]$} & {$[0.240]$} & {$[0.294]$} & {$[0.139 * * *$} \\
Period & $0.233^{* * * *}$ & $0.212 * *$ & $0.212^{* * *}$ & 0.145 \\
& {$[0.086]$} & {$[0.093]$} & {$[0.093]$} & {$[0.093]$} \\
Observations & 88 & 88 & 88 & 88 \\
Log likelihood & -36.40 & -36.40 & -39.31 & -35.05 \\
\hline
\end{tabular}

Notes: Ordered probit regressions; standard errors are clustered by group.

*** Significant at the 1 percent level.

**Significant at the 5 percent level.

* Significant at the 10 percent level.

output, and a number of treatment and control variables, a positive relationship between market-predicted output and the subsequent actual group output. We account for the possibility that this positive relationship is driven by prices merely adjusting to past outcomes, rather than influencing subsequent outcomes, by including the groups' prior period output in the regressions as a control. While there is a strong (positive) relation between a group's output in period $t-1$ and period $t$, period $t$ prices additionally predict group output. ${ }^{21}$ Thus, prices seem to play a critical role in how the market influences the coordination game, beyond simply reflecting information in past outcomes. ${ }^{22}$

\section{Experiment 2: Weaker Complementarities in Production $(j=2)$}

Our first experiment demonstrates a negative effect of asset markets on efficiency in a linked minimum-input coordination game. Our predictions, based on the property that in such games any player can unilaterally lower output, posit that the market's effects should be based largely on the modified incentives produced either by realized or potential portfolio positions. However, the market's effect in our first experiment appears to go further-reducing output even when market incentives are low and when incentives in the game are entirely unchanged, as they are for Outsiders. This finding suggests that, in addition to any portfolio incentive effects produced by markets, there is a market communication effect whereby the market also influences output by negatively affecting players' beliefs.

common in the literature, see Joyce E. Berg and Thomas A. Rietz (2003), we standardize prices such that they add up to one in each market. As a result, we drop observations that do not contain price information for all securities.

${ }^{21}$ Consistent with the idea that subjects use prices to coordinate their behavior, we find that nonequilibrium behavior in the form of input levels that exceed the minimum in the group are lower in the Market treatment compared with the Control treatment. Thus, markets help reduce "wasted input."

${ }^{22}$ The results are qualitatively similar, though statistically weaker, for Outsider groups. 
Our second experiment more directly tests for such a market communication effect by exploring an environment in which the incentive effects produced by the market are very weak. We use a "second-order statistic" coordination game $(j=2)$, in which output is determined by the second-lowest input choice. The portfolio incentive effect when $j=2$ should be nonexistent. For any combination of portfolio holdings, all of the matched input outcomes remain equilibria since no single player can unilaterally determine the output level (see Proposition 1 in the online Appendix). For similar reasons, all equilibria from the game with no market are preserved as fully revealing rational expectations equilibria with the preplay asset market when $j=2$ (see Proposition 2). Therefore, any change in output in this case is unlikely to result from portfolio incentives and is more likely the product of a market communication effect.

\section{A. Experimental Design}

Sessions for this experiment were identical to those for Experiment 1, except that group output in the coordination game in each period was determined by the second lowest input in the group $(j=2$, see Table 7$)$. We used the market payoffs from the Market $L$ treatment from Experiment 1 and changed the instructions only to reflect that the second-lowest choice would determine payoffs in the coordination game. See panel B in Table 2 for summary of the data collected.

\section{B. Results}

The presence of asset markets again induces lower output in all treatments-i.e., for both Large and Small groups and for Insider and Outsider groups- though the effects are not as strong as in Experiment 1 (Figure 2). Table 8 reports ordered probit regressions with group random effects, similar to those for Experiment 1. The results show that output in the Market treatment is significantly lower than in the Control treatment in all specifications, and for both Insider and Outsider groups. ${ }^{23}$

We also look at the relationship between prices and outcomes, where a market communication effect would predict a positive relationship between the output level predicted by the market and actual output. As in Experiment 1, we again construct a measure of price-based expected output. Table 9 shows that price-based expected output is strongly related to group output, controlling for group size, period number, and previous period output. Notably, the coefficient on expected output is larger than for previous period output. As in Experiment 1, the market forecasts future output, indicating a strong role for market prices in coordinating players' beliefs. ${ }^{24}$

\footnotetext{
${ }^{23}$ The adverse market effect on output is roughly half as large in Experiment 2 as in Experiment 1 (controlling for group size and period). This difference is significant at the 1 percent level. In results not reported here we find that Insiders' output is not statistically different from Outsiders' output. Also, in testing whether Outsiders hold different end-of-period portfolios compared with Insiders, we find no statistical difference.

${ }^{24}$ We can also explore the relationship between output in "paired" groups that could observe one another. To do so, we calculate the average output for each group across all eight periods and then compare the output in linked groups. Pooling across the Control (no market) groups in both experiments, there is very little relationship between average output for small groups and the linked large groups (the correlation is -0.06 and is statistically insignificant). This is perhaps not surprising, since there was relatively little variance for small group output in the control treatments. However, pooling across both experiments, the correlation in output between linked Insider/Outsider market groups is much higher (the correlation is 0.56 and is statistically significant at $p=0.002$ ). This pattern is
} 
Table 7-Second-Order-Statistic-Input Game Payoff Table (Exp 2)

\begin{tabular}{cccccc}
\hline \hline & & \multicolumn{5}{c}{$\begin{array}{c}\text { Second lowest input } \\
\text { (output) }\end{array}$} \\
\cline { 3 - 6 } & & 4 & 3 & 2 & 1 \\
\hline & 4 & 2.00 & 1.60 & 1.20 & 0.80 \\
Player's & 3 & 1.80 & 1.80 & 1.40 & 1.00 \\
input & 2 & 1.60 & 1.60 & 1.60 & 1.20 \\
& 1 & 1.40 & 1.40 & 1.40 & 1.40 \\
\hline
\end{tabular}
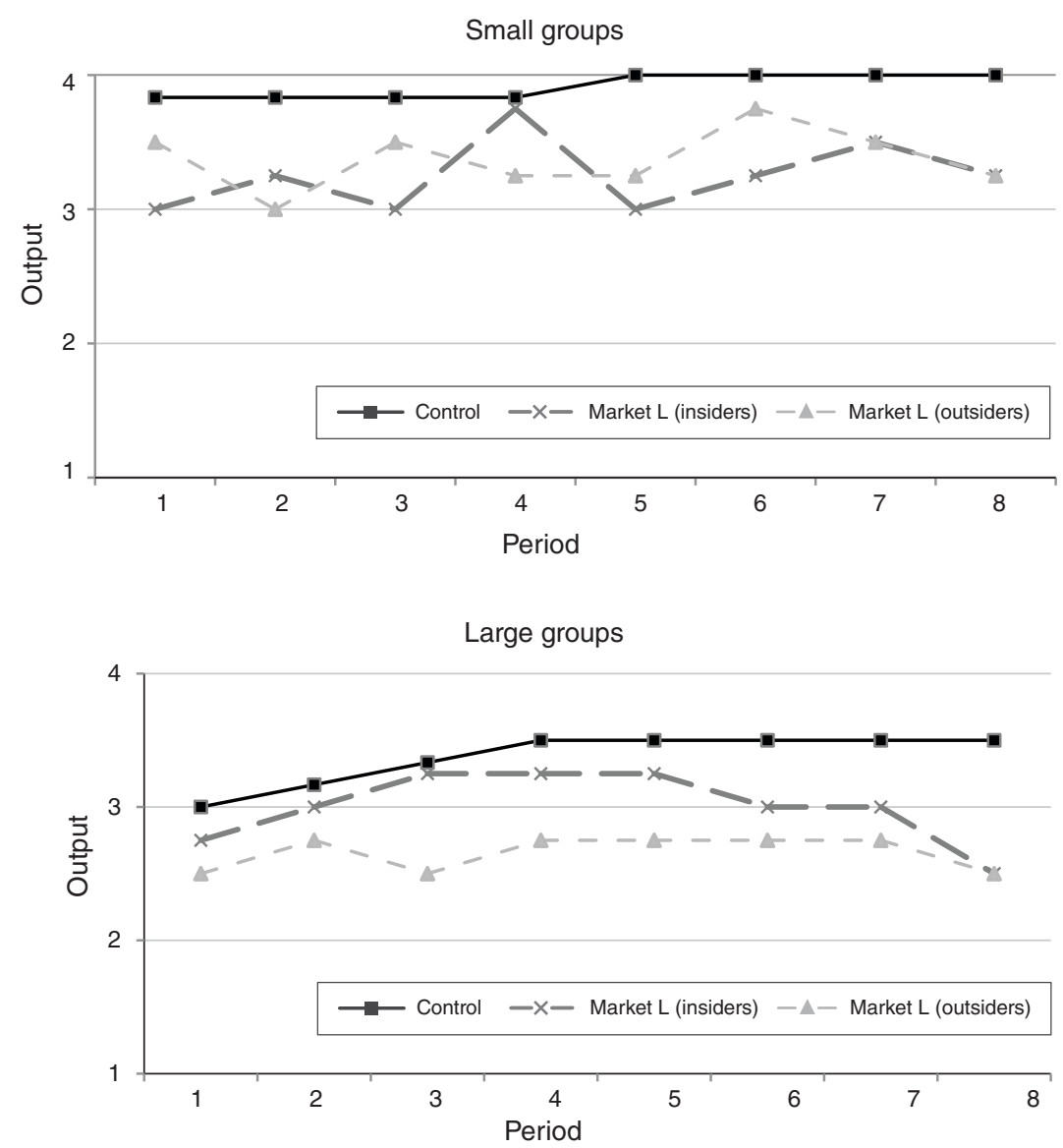

Figure 2. Average Group Output across Periods (Exp 2)

\section{Conclusion}

We explore the relationship between asset markets and underlying economic activity modeled by a coordination game. We find that the presence of an asset market influences aggregate behavior, measured by output in the coordination game, in a significantly negative manner.

consistent with a market communication effect, whereby Outsider market groups are influenced by expectations in their linked Insider group. 
Table 8-Group Output by Condition Relative to Control (Exp 2)

\begin{tabular}{|c|c|c|c|c|}
\hline & \multicolumn{2}{|c|}{ Group output: Insiders (versus Control) } & \multicolumn{2}{|c|}{ Group output: Outsiders (versus Control) } \\
\hline & (1) & (2) & (3) & (4) \\
\hline Market & $\begin{array}{c}-2.739 * * * \\
{[0.651]}\end{array}$ & $\begin{array}{c}-0.862 * * \\
{[0.352]}\end{array}$ & $\begin{array}{c}-3.063 * * * \\
{[0.629]}\end{array}$ & $\begin{array}{c}-3.306 * * * \\
{[0.840]}\end{array}$ \\
\hline Large group & & $\begin{array}{c}-0.406 * * * \\
{[0.135]}\end{array}$ & & $\begin{array}{c}-1.136^{* * *} \\
{[0.272]}\end{array}$ \\
\hline Period & $\begin{array}{l}0.129 * * \\
{[0.063]}\end{array}$ & $\begin{array}{l}0.142 * * \\
{[0.063]}\end{array}$ & $\begin{array}{l}0.177 * * \\
{[0.071]}\end{array}$ & $\begin{array}{c}0.178 * * \\
{[0.071]}\end{array}$ \\
\hline Observations & 160 & 160 & 160 & 160 \\
\hline Log likelihood & -88.58 & -87.51 & -78.55 & -75.12 \\
\hline
\end{tabular}

Notes: Ordered probit regression with group random effects; Huber-White standard errors.

*** Significant at the 1 percent level.

** Significant at the 5 percent level.

* Significant at the 10 percent level.

Table 9-Security Prices and Group Output (Exp 2, Insiders)

\begin{tabular}{lcc}
\hline \hline & \multicolumn{2}{c}{ Group output } \\
\cline { 2 - 3 } & $(1)$ & $(2)$ \\
\hline Expected output & $1.521^{* *}$ & $1.883^{* *}$ \\
Large group & {$[0.760]$} & {$[0.865]$} \\
& & $-0.238^{*}$ \\
Last period output & & {$[0.128]$} \\
& $0.657^{*}$ & 0.511 \\
Period & {$[0.338]$} & {$[0.379]$} \\
& $-0.170^{*}$ & $-0.186^{*}$ \\
Observations & {$[0.093]$} & {$[0.096]$} \\
Log likelihood & & 54 \\
\hline
\end{tabular}

Notes: Ordered probit regressions; standard errors are clustered by group.

*** Significant at the 1 percent level.

** Significant at the 5 percent level.

* Significant at the 10 percent level.

In the first experiment, we find that preplay asset markets significantly decrease output in an economic environment where the high level of input interdependence creates portfolio-based incentives likely to lead to lower input choices. But in the second experiment no player could unilaterally decrease output, and therefore the portfolio incentive effects that potentially exerted great influence in the first experiment were significantly weaker. We nevertheless find that the market significantly diminishes output in the subsequent coordination game. Thus, across all treatments in both experiments, the presence of an asset market decreases output, regardless of group size, the degree of interdependence in the game, and the relative incentives in the market and game. Perhaps most surprisingly, this is true even for Outsiders, whose game is strategically independent of the asset market.

These results suggest that, in addition to any incentive distortion effects produced by the market, a great deal of influence is exerted by a market communication effect, 
whereby prices and trading behavior influence players' beliefs about what will happen in the subsequent coordination game. This is consistent with the fact that in both experiments prices forecast output, and this predictive power goes beyond simply extrapolating from past output levels. Thus, market trading appears informative about likely future output levels, and this kind of implicit communication is selfreinforcing due to the incentive to match others' behavior in the coordination game. In prior research, such communication has generally facilitated coordination on the efficient equilibrium, but here we find strong negative effects.

In the online Appendix, we demonstrate how the presence of a market may exacerbate players' uncertainty and lead to lower output, by examining a particular model of persistent (but small) strategic uncertainty (Proposition 3). We show that if any player has a small amount of "doubt" regarding the actions of the other players then even for order statistics higher than the minimum, such as the second order statistic $(j=2)$, any rational expectations equilibrium entailing higher input is unstable. However, this theoretical analysis makes no prediction regarding the direction of influence of a market when $n=3$ and $j=2$, where we still find a negative effect of the market on output. Therefore, this theoretical account of our experimental findings is only partial-it explains why the introduction of an asset market may lead to lower output in most of our experimental conditions, but not in all of them. Further work should attempt to more precisely identify why the asset markets have a negative influence. Also, given the beneficial effects of communication in prior research, and the fact that some subjects in our experiments attempted to use the market to signal an intention to select high input, ${ }^{25}$ another open research question involves the point at which market communication yields positive effects. Therefore, when generalizing our results it is important to be cautious about the likely possibility that other contexts-for example, those in which input complementarity is weakermay yield a substantively different market influence.

It is also worth comparing our results to those of Van Huyck, Battalio, and Beil (1993), who find that a preplay market leads to coordination on higher (more efficient) equilibria. In our experiment, the preplay asset markets lead to less efficient output levels. This is even true in the particular case in our second experiment where group size is Small $(n=3)$ and the relevant order statistic $(j=2)$ is therefore the median, as in Van Huyck et al.'s experiment. ${ }^{26}$ In this special case we again find that the asset market produces a negative effect on output, providing a compelling comparison of how two different market institutions can lead to very different outcomes when paired with similar games.

We believe the key difference between our experiment and Van Huyck et al.'s to be the symmetry in our asset market that is not present in their study. In their experiment, the market creates jointly held positive expectations of group outcomes

\footnotetext{
${ }^{25}$ While our focus here is on aggregate behavior and outcomes and not on individual behavior, we also examined different bidding strategies used by individual subjects. We created a measure of "optimism signaling," indicating whether in a given period a subject submitted an order to buy asset 4 for a price greater than 0.50 . We found such behavior in both Large and Small groups, with some subjects persistently offering to buy asset 4 across rounds. But we also found that in both Large and Small groups the number of subjects trying to signal optimism decreased in the second half of the session.

${ }^{26}$ Van Huyck, Battalio, and Beil (1993) do not examine such small group sizes, using a group size of nine, but as we note previously smaller groups should generally result in more efficient coordination. Our payoff function is also different than that used by Van Huyck, Battalio, and Beil (1993).
} 
by eliminating those players who do not hold such optimistic beliefs. Therefore, the end result is mutual reassurance among those selected by the market to play the game (Crawford and Broseta 1998). In our setting however, the market allows both positive and negative signals to players, and in addition does not exclude players with beliefs that correspond to the inefficient outcome. Thus, our markets convey strategic uncertainty to players, rather than reducing it as in Van Huyck et al.'s experiment, and allow it to "snowball" into negative expectations about the likely final outcome. The difference between the two experiments can be viewed as contrasting existence results about how markets impact economic outcomes. Real economic contexts in which markets and economic activity are coupled will often resemble one experiment more than the other. We show that considering the precise influence of markets on economic behavior is of significant importance to someone attempting to design a market institution to aid in efficient equilibrium selection.

More generally, our results also stand in contrast to the stylized fact that greater communication facilitates efficient coordination in games like these (Blume and Ortmann 2007; Cooper et al. 1992). We demonstrate that allowing players to interact via asset markets linked to multiple equilibria, which allows rich and costly communication of intentions and beliefs, has a negative influence on which equilibrium obtains. In this regard, our work is similar to theoretical work demonstrating the potentially harmful effects of public information, including endogenously generated public signals (Stephen Morris and Hyun Song Shin 2002; George-Marios Angeletos and Ivan Werning 2006; Frank Heinemann, Nagel, and Peter Ockenfels 2004 ) in coordination games with incomplete information (global games). However, while this prior work demonstrates that such public information can induce multiple equilibria, where incomplete information would otherwise yield uniqueness, our results demonstrate how such a signal, when generated by a two-sided asset market, can make the inefficient low-output equilibrium more likely. Future research might therefore examine the correspondence between these two sets of results.

Outside the laboratory, markets often have enticing information aggregation and forecasting possibilities when linked to some kinds of economic activity. Yet our work suggests that in some settings the markets themselves might influence the eventual realization of the economic outcome and, worse yet, may do so negatively. For example, many firms have implemented prediction markets to forecast outcomes such as sales and product quality (Bo Cowgill, Justin Wolfers, and Eric Zitzewitz 2008; Wolfers and Zitzewitz 2004). Given that in such settings market traders may have the ability to influence outcomes, our results suggest that the presence of production-linked asset markets may negatively influence outcomes both by creating incentive problems and by pessimistically influencing beliefs. Additionally, many macroeconomic models rely upon some relationship between expectations and productivity, as in our underlying game (Bryant 1983; Cooper and Andrew John 1988). Given markets' role in communicating and influencing expectations in our experiment, real-world markets may sometimes similarly play an important role in contributing to shifts into inefficient equilibria. Thus, for example, economic crises may be exacerbated by economic agents focusing their attention on market behavior, which may create self-reinforcing pessimistic beliefs. Broadly, our work suggests that whenever economic activity involving high degrees of complementarity is linked to asset markets, policymakers may want to explore the possibility of perverse effects of the kind we have found here. 


\section{REFERENCES}

Aït-Sahalia, Yacine, and Andrew W. Lo. 1998. "Nonparametric Estimation of State-Price Densities Implicit in Financial Asset Prices.” Journal of Finance, 53(2): 499-547.

Angeletos, George-Marios, and Ivan Werning. 2006. "Crises and Prices: Information Aggregation, Multiplicity, and Volatility." American Economic Review, 96(5): 1720-36.

Berg, Joyce E., and Thomas A. Rietz. 2003. "Prediction Markets as Decision Support Systems." Information Systems Frontiers, 5(1): 79-93.

Blume, Andreas, and Andreas Ortmann. 2007. "The Effects of Costless Pre-Play Communication: Experimental Evidence from Games with Pareto-Ranked Equilibria." Journal of Economic Theory, 132(1): 274-90.

Bornstein, Gary, Uri Gneezy, and Rosemarie Nagel. 2002. "The Effect of Intergroup Competition on Group Coordination: An Experimental Study.” Games and Economic Behavior, 41(1): 1-25.

Brandts, Jordi, and David J. Cooper. 2006. "Observability and Overcoming Coordination Failure in Organizations: An Experimental Study.” Experimental Economics, 9(4): 407-23.

Bryant, John. 1983. “A Simple Rational Expectations Keynes-Type Model.” Quarterly Journal of Economics, 98(3): 525-28.

Camerer, Colin F. 2003. Behavioral Game Theory: Experiments in Strategic Interaction. Roundtable Series in Behavioral Economics. Princeton, NJ: Princeton University Press.

Camerer, Colin, and Marc Knez. 1997. "Coordination in Organizations: A Game-Theoretic Perspective.” In Organizational Decision-Making. Cambridge Series on Judgment and Decision Making, ed. Zur Shapira, 158-90. New York: Cambridge University Press.

Cooper, Russell W. 1999. Coordination Games: Complementarities and Macroeconomics. New York: Cambridge University Press.

Cooper, Russell, and Andrew John. 1988. "Coordinating Coordination Failures in Keynesian Models." Quarterly Journal of Economics, 103(3): 441-63.

Cooper, Russell, Douglas V. DeJong, Robert Forsythe, and Thomas W. Ross. 1992. "Communication in Coordination Games." Quarterly Journal of Economics, 107(2): 739-71.

Cowgill, Bo, Justin Wolfers, and Eric Zitzewitz. 2008. "Using Prediction Markets to Track Information Flows: Evidence from Google.” Unpublished.

Crawford, Vincent P. 1995. “Adaptive Dynamics in Coordination Games.” Econometrica, 63(1): $103-43$.

Crawford, Vincent, and Bruno Broseta. 1998. "What Price Coordination? The Efficiency-Enhancing Effect of Auctioning the Right to Play." American Economic Review, 88(1): 198-225.

Devetag, Giovanna, and Andreas Ortmann. 2007. "When and Why? A Critical Survey on Coordination Failure in the Laboratory." Experimental Economics, 10(3): 331-44.

Fischbacher, Urs. 2007. "Z-Tree: Zurich Toolbox for Ready-Made Economic Experiments." Experimental Economics, 10(2): 171-78.

Forsythe, Robert, Forrest Nelson, George R. Neumann and Jack Wright. 1992. "Anatomy of an Experimental Political Stock Market.” American Economic Review, 82(5): 1142-61.

Harrison, Glenn W., and Jack Hirshleifer. 1989. “An Experimental Evaluation of Weakest Link/Best Shot Models of Public Goods.” Journal of Political Economy, 97(1): 201-25.

Hayek, F. A. 1945. "The Use of Knowledge in Society." American Economic Review, 35(4): 519-30.

Heinemann, Frank, Rosemarie Nagel, and Peter Ockenfels. 2004. "The Theory of Global Games on Test: Experimental Analysis of Coordination Games with Public and Private Information." Econometrica, 72(5): 1583-99.

Hirshleifer, Jack. 1983. "From Weakest-Link to Best-Shot: The Voluntary Provision of Public Goods." Public Choice, 41(3): 371-86.

Knez, Marc, and Colin Camerer. 1994. "Creating Expectational Assets in the Laboratory: Coordination in 'Weakest Link' Games.” Strategic Management Journal, 15(S1): 109-19.

Morris, Stephen, and Hyun Song Shin. 2002. "Social Value of Public Information." American Economic Review, 92(5): 1521-34.

Smith, Adam. 1776. The Wealth of Nations. New York: Modern Library (reprinted 1994).

Van Huyck, John B., Raymond C. Battalio, and Richard O. Beil. 1990. "Tacit Coordination Games, Strategic Uncertainty, and Coordination Failure.” American Economic Review, 80(1): 234-48.

Van Huyck, John B., Raymond C. Battalio, and Richard O. Beil. 1991. "Strategic Uncertainty, Equilibrium Selection, and Coordination Failure in Average Opinion Games." Quarterly Journal of Economics, 106(3): 885-910.

Van Huyck, John B., Raymond C. Battalio, and Richard O. Beil. 1993. "Asset Markets as an Equilibrium Selection Mechanism: Coordination Failure, Game Form Auctions, and Tacit Communication." Games and Economic Behavior, 5(3): 485-504. 
Van Huyck, John B., Raymond C. Battalio, and Frederick W. Rankin. 2007. "Evidence on Learning in Coordination Games." Experimental Economics, 10(3): 205-20.

Weber, Roberto A. 2006. "Managing Growth to Achieve Efficient Coordination in Large Groups." American Economic Review, 96(1): 114-26.

Weber, Roberto, Colin Camerer, Yuval Rottenstreich, and Marc Knez. 2001. "The Illusion of Leadership: Misattribution of Cause in Coordination Games." Organization Science, 12(5): 582-98.

Wolfers, Justin, and Eric Zitzewitz. 2004. "Prediction Markets." Journal of Economic Perspectives, 18(2): 107-26. 